\title{
The Community Youth Outreach Programme In Delta, British Columbia, Canada: "The Personal Touch That Works"
}

\author{
Sherman Chan, Hardeep Thind and Lesley Lim
}

\begin{abstract}
With Canada's strong multicultural policy, immigrants are encouraged to maintain their cultural values and expectations while adjusting to a new country. This in mind, the, Surrey Delta Immigrant Services Society partnered with the British Columbia Ministry Responsible for Multiculturalism and Immigration, British Columbia Ministry for Children and Families, and the Delta School District to develop a programme which assists new immigrant youth, theirfamilies and their community. It provides an innovative approach to assist with language and cultural interpretation as well as school based initiatives for all parties involved. Thus, this paper is a description of the Community Youth Outreach Programme in Delta, British Columbia and a discussion of the key features that
\end{abstract}

Sherman Chan, MSc in Applied Social Studies. Director of Service Quality and Human Resources at Surrey Delta Immigrant Services Society. He has over 25 years of working experience in the social services field and is a registered social worker as well as a member of the $B C$ Association of Social Workers. He is also a Member of BC Settlement and Integration Workers' Association and the treasurer of the Canadian Council for Refugees.

Hardeep Thind, BA in Communication. Punjabi/ Hindi Speaking Youth Integration Worker with Community Youth Outreach Programme at Surrey Delta Immigrant Services Society. She has over ten years experience working with the South Asian community. She is a founding board member of the Surrey Delta Multiculturalism Coordinating Society.

Lesley Lim, BA in Law/Sociology with a concentration in Criminology and Criminal Justice. Cantonese/Mandarin Speaking Youth Integration Worker with the Community Youth Outreach Programme at Surrey Delta Immigrant Services Society. She has over seven years experience in working with disadvantaged youth, delinquent youth and immigrant youth and their families. address the needs of immigrant and refugee students and their families while affirming their culture and linguistic background in a demographically $d y$ namic area.

\section{Résumé}

La politique multiculturelle très sérieuse du Canada encourage les immigrés à maintenirleurs valeurs et leurs attentes culturelles tout en s'adaptant à un nouveau pays. Aussi, l'Association pour services aux immigrés de Delta Surrey (Surrey Delta Immigrant Services Society), s'est-elle associée avec le ministère de la Colombie-Britannique chargé de la politique multiculturelle et del'immigration, leministère de l'enfant et de la famille de la ColombieBritannique et la Delta School District pour développer un programme d'aide aux jeunes immigrés fraîchement débarqués, leurs familles et leur communauté. Ce programme propose une approche nouvelle pour soutenir les efforts en matière d'interprétation de la langue et de la culture, ainsi que les initiatives en milieu scolaire, pour toutes les parties concernées. Ce document contient donc une description $d u$ Programme communautaire d'intervention auprès de la jeunesse de Delta, en Colombie-Britannique, ainsi qu'une discussion des éléments clés qui répondent aux besoins des étudiants immigrés et réfugiés et de leurs familles tout en affirmant leur culture et leur origine linguistique dans une région à démographie très dynamique.

\section{The Community of Delta: Rich Diversity}

Delta derives its name from the fertile delta of the Fraser River. It is strategically located within a region of $1.8 \mathrm{mil}-$ lion people and is linked to the Greater Vancouver Regional District, the United States of America and the Pacific Rim by road, rail, air, sea and river (Corporation of Delta 1998). Delta has a population of 95,411 and 40 percent of them are between 20 and 44 years old. Fifty percent of its population is employed in the labour force. According to the 1996 Statistics of Canada census, 20 percent of Delta's population was foreign-born. Of all the foreign born population, 25 percent is of South Asian (Punjabi, Hindi, and Urdu) ethnic origin, an increase from 11 percent in 1986 while 12 percent is Chinese (Cantonese and Mandarin), an increase from four percent in 1986 (BC Ministry Responsible for Multiculturalism and Immigration 1999).

\section{Surrey Delta Immigrant Services Society (SDISS)}

SDISS is a non-profit Society whose mandate is to promote the independence of immigrants and to build strong, culturally diverse communities. It provides a range of information, counselling, language and employment services to children, youth, adults and families in Surrey, Delta and the surrounding areas in British Columbia, Canada. The adjustment which newcomers must make in immigrating to Canada can be made much easier with assistance from immigrant and refugee services delivered in the native language in a culturally sensitive manner.

A volunteer Board of Directors governs SDISS. Currently there are $71 \mathrm{mul}$ tilingual staff, 236 interpreters and 115 volunteers who offer language and culture specific services. Last year, the Society provided more than $30,000 \mathrm{cli}$ ent contacts to immigrants and refugees. The budget for the fiscal year $1999 / 2000$ is $\$ 3.8$ million. Among the various programmes which stands out includes: the Community Youth Outreach Programme. 
The Community Youth Outreach Programme addresses the needs of immigrant and refugee youth that are new to Canada. In encountering a new land, they face barriers and problems of adjustment and integration that hinder their social development and learning. They tend to become isolated from the mainstream life of school and community activities because they are still learning English and because of differences in culture and upbringing. Some of them also face family separation due to international business ownership, resulting in arrangements in which the mother and the children live in $\mathrm{BC}$ but the father is based in Hong Kong; in other cases the children live in BC while both parents live in Taiwan.

The discussion in this paper is divided into four major parts. First, it introduces Canada's policy on multiculturalism. Second, it reviews the ESL policy and philosophy of the Delta School District. Third, it presents the Community Youth Outreach Programme and explores its key components. Last, it examines the innovative aspects of the programme and why it works.

\section{Youth in Transition and Multiculturalism in Canada}

A number of predominant models developed by researchers to assess the psychological adaptation of immigrants and refugees in the host society were taken into consideration in the development of the Community Youth Outreach Programme. According to Sayegh and Lasry (1993), the model of assimilation talks about the process of social transformation that promotes successful assimilation and which occurs when immigrants identify completely with the new society at the expense of their cultural identity. However, the Canadian multicultural policy is based on a "cultural mosaic" framework. The framework was developed using Berry's model of Acculturation (Berry 1980, 1984). Acculturation, according to Berry, is a broadly defined process in which the native language and culture is maintained and supported, while the second language is developed and the individual adjusts to their new culture. This model informed the design and development of the Programme. This model of acculturation identifies changes within both immigrants and host society as a result of contacts. Acculturation can be seen as the selective adaptation of value systems and processes of integration and differentiation. Berry's model suggests that immigrants and refugees must redefine themselves towards both the new culture and their own cultural values. In this model there are four possible outcomes of this identity process:

1. Assimilation-to give-up one's cultural values in order to be accepted into the dominant cultural values.

2. Integration -to retain one's cultural values as well as acquire new cultural values.

3. Separation -to only retain one's cultural values and not to accept new cultural values.

4. Marginalization -to maintain a part from one's cultural values and new cultural values. (Berry 1980, p.227)

Of these four possible outcomes, integration appears to be the preferred outcome of the Canadian multicultural policy and settlement practices. Integration is a long term, two-way process in which immigrants and refugees achieve full participation in all aspects of Canadian life and Canadian society. Newcomers can benefit from the full potential of their newly adopted land (See also Cummins 1996).

Since immigrant and refugee youths new to Canada confront difficulties in a country that, although it offers them opportunities, speaks a language they do not know. They are also unfamiliar with the way of life. Until their language skills are developed, their inability to communicate isolates them from peers and school activities (Handford et .al 1993). Some of them have experienced disruption in their education, e.g. war, refugee camp or uprooting due to emigration. Some, because of the stigma attached, keep their refugee identity and status a secret from their peers. Of course, this secrecy is a way to conceal their vulnerability. The report, "After the Door has been Opened" (Minister of
Supply and Services Canada 1988) points out that children and youth must prepare themselves to be adults in Canadian society. Their opportunities come from experiences of success in school, from important adults, and their peers. However, under many circumstances, as highlighted above, instead of success, immigrant and refugee youth encounter frustration because of language difficulties, the fear of refugee stigma, the inability of the guardians to understand their needs and the demands of integrating into anew culture. Without appropriate guidance and support, the children and youth become margina-lized leading todistress, isolation and social dysfunction (Igoa 1995).

The Canadian Council for Refugees (1998) explores the meaning of settlement and integration and presents guidelines for best practices as well as examples of programmes worth emulating. The design of the Community Youth Outreach Programme incorporated these guidelines. British Columbia's Ministry for Children and Families in the Delta area was supportive of this programme because it was considered a preventive approach: the more assistance new immigrant youth and their families receive now, the less likelihood of them needing to access services in the future.

English as a Second Language (ESL) System in the Delta School
District The philosophy of the ESL programme in the Delta School District is that all students, regardless of their linguistic and cultural background, will have the opportunity to develop their potential to the fullest extent. Integration is the main focus and mutual respect between different cultures must be encouraged. The district also believes that the degree of success of the ESL programme depends, to a large extent, on the amount of interaction and understanding between the student, the school and the student's home.

Multicultural Services are offered through a multicultural worker. The multicultural worker's role differs from the Youth Integration Worker's in that she or he is involved in the assessment 
process and placement of ESL students while the Youth Integration Worker is not. A large part of the multicultural worker's time is spent doing such work in the district's elementary schools. She is also involved in promoting acculturation, multiculturalism, social harmony and facilitating communication between home and school.

Based on the statistics provided by the district, there were 1508 ESL students served in the 1997-1998 school year. This was the last year that such statistics were available. The north end of Delta accounted for 89 percent of the district's total ESL population (Delta School District, 1996, English as a Second Language: Population Growth and District Response Report; Delta School District, 1996, Special Programmes Resource Binder, p. 2-20). Thus, this is where the Youth Outreach Programme is focused.

\section{The Launching of the Community Youth Outreach Programme}

The fall of 1993 was the launch date for the Community Youth Outreach Programme. A Punjabi/Hindi and a Cantonese/Mandarin speaking Youth Integration Workers were stationed at two schools. The Director of Special Programmes of the Delta School District where the ESL programme resides made the decision about location. A major criterion was a high enrollment of new immigrant and refugee students. Based on this, a junior high school (grades 810 ) and a secondary school (grades 912) in the north end of the district benefited from the assignment of Youth Integration Workers. The junior high school provided the Youth Integration Worker with an office and a phone, which were later realized to be essential items. In addition, they were welcomed into the classroom during school time, another essential element to the programme's success, because if the workers were to build rapport with the students and the staff, thye had to be highly visible. An important strategy to this would be to spend lunch hours with the youth, visit them on the soccer field, basketball court, or walk the hallways with them. Once the immigrant youth feels comfortable with the worker, he or she will start to seek out the worker on his or her own.

The programme provides services to all new immigrant youth and their families regardless of their status. The mandate of the programmeme is to address the needs of these students and their families who are new to the community and the school. The programme assists them in overcoming adjustment and integration problems. Some have specialized problems, for example, family separations mentioned earlier.

The Youth Outreach Programme had a very successful first year (1993). This was largely due to the fact that the programme was placed in schools with administrators who are committed and accommodative of these students' school needs. The teachers and principals were extremely helpful with the extra resources they provided. They saw this as a win-win situation because they were dealing with the influx of immigrants with no additional help before.

With such a positive first year, the programme was expanded to serve three schools on a full-time basis and serve other schools on an "as needed" basis. The served schools are finally feeling that they are reaching out and connecting with parents and youth. The outcome is that all stakeholders, parents, teachers, administrators and youth, are grateful for having on site workers who do more than interpreting for them. They are very pleased with the community orientation, ethnocultural community connections and after school activities such as a field trips to the Science World, that were not being provided before. Recently, other schools in the district with a growing number of immigrant youth have been very vocal about the need for similar services.

The Programme can be divided into fivecategories: (a)Community Orientation; (b) School Orientation; (c) AfterSchool Activities; (d) Individual Guidance; and (e) Parents' Group.

\section{Community Orientation}

For children who are resettled, being in a new environment can be overwhelm- ing, particularly if this new environment is one's new country of residence. They must learn everything all over again: how to use public transportation, obtain a social insurance number and use bank services. Thus, the purpose of the community orientation is to assist the students who can, in turn, assist their parents on basic knowledge of how to use public services. One effective way to do this is through field trips. Most field trips are planned using public transportation and the students usually choose the destinations. It is an opportunity for students to go to some of the athletic games, different educational settings and points of interest that they have heard about but may not have had the means to attend. The programme subsidizes the field trips, making them more accessible for students and on a few occasions, due to the family's lack of financial resources, the expenses of the trips are fully funded by the programme. These activities allow the students to build their confidence so that subsequently they can take their families on similar trips. For instance, three years ago, a student came to school on a Monday and was excited to share what she did on the weekend. She wanted to do something special for her younger sister's birthday so she suggested to her parents that the family (about fourteen members, including her aunts and uncles) go bowling. They were quick to say that it was too expensive and dangerous. However, she pointed out: "I have gone with the school and I am still in one piece." The parents then allowed the fifteen-yearold daughter to phone the bowling alley and to make some inquiries. She explained to the owner of the bowling alley that she had come with the school and was interested in bringing her family. The gentleman remembered the group and ended up allowing her family to bowl one extra game after seeing how much fun the family was having trying out a new game. The parents were sore the next day but they mentioned, during parent teacher interviews, that they were grateful the programmeintroduced their children to different recreational places in the com- 
munity. They expressed that they did not have the time or enough English to do these kinds of events on their own, nor would they allow their children and their friends to do so without being introduced first. Once the immigrant youth feels comfortable and knowledgeable about the resources in their community, they do not feel alienated. Breaking down the barriers or the fears of the unknown makes their surrounding community less foreign and intimidating.

\section{School Orientation}

The culture shock of being in a new country and the need to learn about the Canadian school system can be quite overwhelming. Therefore, this programmehelps tobridge the gap between new and old environment for the students as well as the parents. The Youth Integration Worker also provides oneon-one guidance with the families to explain school rules, timetables and required school supplies.

For new immigrant students, school orientation is the same process as for any new student, except the Youth Integration Worker gives them a tour and information about their new school in their native language. The family is assisted with interpretation and the new student is assigned a buddy with a boy or girl from the same country or who speaks the same language. On a few occasions, when language is a barrier, the settlement counsellors from SDISS are called to the school for assistance with languages not known by the Youth Integration Worker.

The parents are very pleased with the one-on-one guidance service because schooling in Canada is different from their native country's schooling. In India, for example, students go to school six days a week, there are no co-ed classes, no bells to signal the start and end of class, and teachers are referred to as "madam" or "sir," and not by their last name. There, teachers are given the responsibility to be disciplinarians, whereas in $B C$, that is not the case. Often, parents have told the school to punish their child anyway they deem fit.
However, the teacher and principal always inform the parents that discipline is their responsibility not the school's.

One noticeable change since the programme started has been the increase in immigrant parents attending parentteacher conferences. The reasons are twofold. First, parents are contacted in their native language either by telephone or by sending home translated parent-teacher interview forms, to which they can respond in their native language. Second, since they know the Youth Integration Worker will be available to assist them to speak to the children's teachers, parents gain confidence in attending the sessions. A few even tried to speak for themselves and the youth worker needed only to interpret a few words. This indirectly help the parents' self-esteem. The parents feel that the Youth Integration Workers understand them and they are there to help.

\section{After-School Activities}

The after school activities component has a two-part objective: a neutral territory to gain more insight into the youth as well as an opportunity for the immigrant youth to learn something new. This neutral territory is a place where students can go freely with no expectations to share their resettlement experiences or to engage in conversation. This does not put the youth on the spot as they might feel when they are in their academic setting. It is also a venue for students to work on their social skills such as teamwork, and communication and leadership skills.

The after-school activities were designed for the purpose of connecting with the immigrant youth in a nonthreatening environment. It was believed that an activity such as basketball introduced after school would attract more students. Ultimately the goal was to build trust with the youth. After the initial after school activity, it was realized that the games or sports which Canadian born students had grown up playing, were quite different from those of immigrant students. In a particular case, when a group of students were setting up the volleyball net outside af- ter school, some of the South Asian girls started running around the field. It appeared to be tag to Canadian students but they were informed that it was "khokho" a form of tag that is very popular in India where all the girls get together and play. The original idea wasn't to play "kho-kho" but after having learnt the new game, other days were set aside to play it. In addition to the sports activities, time was set aside to play Chinese chess and "bhabhi" a card game that is popular in India. On these occasions, Canadian students were invited to learn games from other cultures which they enjoyed very much. Other extra-curricular programmes such as the GOAL club were also created to support the acculturation process while developing leadership skills.

\section{“GOAL Club:” Developing Future Leaders}

In addition to the after school activities, a club was started for the new immigrant students at one of the high schools. The students named it GOAL (Globe of All Languages) Club. The primary objective of the club was to assist students with their integration into school life. Many students came from their former schools as leaders but felt intimidated to join any school group in Canada. The focus of the club was to organize activities such as cultural appreciation days, publish newsletters and organize field trips. The students were full of pride and wanted to share their cultures and celebrate their festivals and other significant dates at the school. The Chinese students, for example, organized a Chinese New Yearcelebration, which other ethnic students helped to serve on that day. The students' enthusiasm was evident in their passion, preparing the dishes and making displays with great pride. The students felt that they were able to contribute and enhance the school life. They were also very proud to share their cultural festivals with their teachers and Canadian peers. These types of events can be a morale booster for students who are looking for a place to fit in.

A newsletter committee was established as well for students' voices to be 
heard. The newsletter was distributed to staff at the school and many teachers found them to be a wealth of information. Articles included topics such as: "Being New to Canada," "Seeing Snow for the First Time," and "Feelings We Had When We Got Off the Plane." Sharing cultural information, advertising for up-coming events, event summaries, and student poetry were published. An immigrantstudent wrote the following article.

\section{Snow}

I woke up one morning and I saw snow. It was just like little pieces of crushed ice, dancing down from heaven with the wind's direction. I acted like how Israelites first saw manna. I ran to my room and wrapped myself up in order to go out. "I got to go out and feel it myself," I said to myself. "How can I describe snow to my friends in Taiwan when I did not feel it myself!" I rushed out and was amazed at how calm everything was. I tried to hold the snowflakes with my hand, but they immediately melted. - I still remember the prayer my brothers and I said that night. "Please God," we begged, "can we have more snow tomorrow?"

In two of the last three years, a multicultural programme in the evening "Talent and Fashion From Around the World" was produced by the GOAL club members. This show was an opportunity for the students to showcase their talents as well as their native attires. Students were involved in singing, dancing, modelling and playing musical instruments. Many hours went into rehearsing for the programme but, at the end, the students felt a genuine sense of school pride and were pleased with their accomplishments. The responses from the students demonstrated that these shows boosted self-esteem for the students and their parents. The audience showed their enthusiasm by asking for another show next year. In particular, many teachers were pleasantly surprised to see "their quiet, shy and reserved ESL students shining like a bright light on stage." They saw a side of the students that they would never have seen otherwise.
Ideally, it would be great for a club like this one to link up with the student council and have a joint venture. Unfortunately, it has been the experience that once the student council gets involved many of the immigrant and refugee students take on a quiet role again. The reasons may be that the student council has a wider perspective than the GOAL club and also the immigrant and refugee students may feel shy about their ability to express their views and communicate fluently in English. Slowly as the immigrant students build their English and self-esteem, a joint venture like this could be undertaken again. Immigrant and refugee students also have individual needs for emotional support. The individual guidance component serves in this area.

\section{Individual Guidance}

The majority of the Youth Integration Worker's time is spent with newcomer youth in providing individual guidance. Since the youth workers do not have a counselling background, only guidance is provided to the youth and their families. Common issues for these students are: "being afraid," "confused," "scared," or "unhappy" in the new environment. Most of these issues stem from culture shock and isolation. The youth often have a hard time adjusting to new cultural values. Their selfidentity is challenged because they are now caught between two cultures. The parents' experience may not be similar because they may have limited contact outside of the home. The youth are trying hard to "fit in" as quickly as possible, sometimes giving up their own cultural beliefs and values. Thus, parents and youth often have a difficult time dealing with intergenerational conflict. Referrals are made mostly through the ESL teachers, some through other class teachers, some are self-referrals, and others are done by school administrators.

If an issue arises that requires counselling, the school counsellor is contacted and the student is referred to him or her. However, if there is a language barrier, the Youth Integration Worker is usually present in the counseling ses- sions. Sometimes a referral is made out of the school and the appropriate agency would be involved with the youth. The Youth Integration Worker may still assist if either the outside agency or the youth request it.

Since the Del ta area office of the Ministry for Children and Families does not have any Punjabi or Chinese speaking social workers, the Youth Integration Workers have assisted them on numerous cases. Last year a 17 year old South Asian girl was apprehended due to physical abuse in her home and the Youth Integration Worker worked with the social worker advising what would be culturally appropriate while also assisting the social worker on home visits. The social worker stayed in touch with the student through the Youth Integration Worker and not the school counsellor in this case. In another incident, theimmigrant youth did not speak either Punjabi or Chinese, but the Youth Integration Worker assisted with the entire removal process as well. The youth wanted a familiar person to escort her with the social worker to her home and then to foster care. The Youth Integration Workers are bound by the same legal requirements that teachers and social workers must abide by regarding confidentiality of information disclosed by a student about abuse, neglect or suicidal thoughts or intentions.

Many immigrant youth are apprehensive about going to the school counsellor. Hence, they usually get there with the assistance of the ESL staff or the Youth Integration Worker. Most eastern cultures discourage any conversation about the family to outsiders. Family issues are to be kept within the family, therefore many immigrant families have frowned upon counseling generally. However, depending on the severity of the issues, parents may be contacted and strict terms of confidentiality are afforded to the parents also. Establishing contact between the families and schools is important to start the process of trust building.

\section{Parents' Group}

In addition to providing support to the immigrant youth, the Community 
Youth Outreach Programme has also focused on providing services to parents who are refugees or immigrants. The establishment of a parents' group was attempted in the first few years, but with only one successful attempt in getting the parents together. However, in the last year and a half, another parents' group has been successfully established. The group was originally developed around their needs and concerns about being more informed of their children's education. They realized that the schooling system in Canada is very different from where they come. Yet they were unable, due to the lack of understanding and language skills, to fully grasp all that they need to know about their children's education and the Canadian school system. They wanted to be informed and ultimately to be able to make informed decisions regarding their children's educational goals. Neither do they want to place complete trust or responsibility in the children to tell and explain school procedures, given that the children may act in their selfinterest and alter information sent home by teachers. Thus, all parties, i.e: parents, school counsellors, ESL teachers and the Youth Integration Worker, saw the Parents' Group to be an answer.

Since the parents' group was created, all communication is done in the native language, Mandarin in this particular Parents' Group. The mandate of the parents' group is threefold. First, the parents' group serves as a support group. A monthly meeting is held for them to come meet and makenew friends in a new environment so that they won't feel so isolated and alone. Second, the group organizes activities that allow the parents to do fun things, be informed and be educated. Some of the activities that have been organized so far are: workshops on the Registered Retirement Savings Plan, taxation, environmental awareness, entrance to university, weeklybadminton evenings and western cooking classes. This was organized due to the numerous comments that immigrant parents have regarding unknown foods, such as squash, that they saw in the grocery store but did not know how to cook.
Third, the group meetings serve as a means of communication to inform and update. This is accomplished by distributing monthly newsletters that are published by the parents to inform all parents about upcoming school events, community events and issues relating to immigration and families.

In addition, in the past year the parents have put together an "Asian New Year Teacher Appreciation Luncheon" that was a grand success. The parents' group wanted to show their appreciation and respect to the school and the teachers for their dedication, since teachers are highly respected in eastern cultures. The teachers at that particular school were given a true taste and experience of Asian culture and New Year celebrations. Many parents were professionals back home and miss the ability to contribute positively to their community and environment due to their lack of language abilities or their perception of their lack of language abilities. Loss of status and professional opportunities are two major concerns that affect immigrant parents. The parents' group indirectly assists in building their self-esteem and self-worth in a new environment and country. Many immigrant parents, similar to the "mainstream" parents have a great deal to offer to the school, however, an appropriate avenue is not always apparent. Joining the Parents' Advisory Council at their school seems to be too overwhelming for them given their language and cultural barriers.

\section{Lessons Learnt: The Personal Touch That Works}

The Youth Integration Workers have a very close working relationship with the ESL teachers. Since most immigrant students receive English support, the department was a natural tie-in with the programme. As mentioned earlier, due to the "open door policy" of the ESL department and the schools, the Youth Integration Workers have spent many hours with the youth directly in the classroom providing easy access to the students.

The obvious assistance the school knew it would receive was the interpre- tation services. Since the two Youth Integration Workers are able to speak the language of 88 percent of its immigrant student population (Punjabi, Hindi, Cantonese and Mandarin), communication between home and school could easily be facilitated. On site Youth Integration Workers who serve as language and cultural interpreters, are available to deal with daily school issues with the youth as well as to notify parents if issues were of concern to them. This flow of communication makes the daily routines of the schools run much smoother than ever before.

The essential ingredient to any programme's success is building a solid foundation from which the programme can continue to grow. The overwhelming positive response from the Delta School District was instrumental to the success of this programme. This was in the form of partial funding and supporting Special Programmes coordination. Due to the flexibility of the District and most certainly of the schools, the programmehas been to mould itself to meet the needs of immigrant youth, their families and the schools.

Over the years, recognition for the programmehas come in the form of personal testimonies from students in our annual surveys. They emphasize how the programme has enriched their lives and provided a means for a smoother integration process. Letters of support and feedback from school principals, counsellors, teachers and parents as to the "excellent and essential resource service in meeting the needs of a diverse and multi-faceted population" have served as the programme's measurement of its benefits. Consistently, the assets of the programme have been its ability to: assist with the understanding of intergenerational adaptation; alleviate potential tensions and promote understanding between different eth-nocultural communities; connect immigrant youth and their families to local community resources; help reduce incidents of conflicts between the differentethnocultural communities; serve as an early intervention of immigrant youth and their families in need of addi- 
tional assistance; educate new immigrant youth and their families of Canadian society; help reduce isolation and increase self-esteem; and help in the settlement and adaptation process. The ultimate goal of parents and students is to become integrated into the Canadian community.

The major obstacle the programme may face in the future will be lack of continued funding from the government. This programmehas to apply for funding each year and the government may change its funding priority from preventative and support services to remedial service. In such a case, the programme would lose its funding. Another challenge for the programme is that with the addition of a third base school, the Youth Integration Workers have been busy meeting the demands of the third school as well as the many other schools calling in for service. In order for this programme to be effective and not to "spread too thin," additional resources need to be deployed at this crucial juncture.

\section{Conclusion}

Integration issues for immigrant and refugee youth vary from the initial adjustment to peer support, school life, community surroundings and to long term issues. All of them require a collaborative scheme to adequately deal with them. Language and cultural values were identified as the most important adjustment issues youth face.
These make it difficult for youth to understand and adapt to the Canadian culture, the school system, or make friends. The difficulty that parents face in securing gainful employment, the change in lifestyle and parental role, which may not be positive, also play an important role in how youths get adjusted to their new homeland.

With the help of the Youth Integration Worker, immigrant and refugee youth and their families are better prepared to adapt to Canada and to live a productive life. The challenge rests with the immigrant serving agencies, schools and government agencies to collaborate so that their services support immigrant and refugee youths in their efforts to become productive members of their new country while respecting their own culture and personal integrity.

\section{References}

BCMinistry Responsible for Multiculturalism and Immigration. 1999. A Profile of Immigration to British Colombia regions and communities, 1986-1996, pp. 67-69.

BC Ministry of Education, Special Programmes. 1999. ESL (English as a Second Language) Policy, Guidelines and Resources for Teachers, p. 7.

Berry, J.W. 1984. Multicultural Policy in Canada: A Social Psychological Analysis. Canadian Journal of Behavioural Science, 16(4), pp. 353-370.

Berry,J.W.1980. Acculturation as Varieties of Adaptation. In A. PADILLA (Ed.), Acculturation: Theory, Models and Some
New Findings. Colorado: Westview Press Inc.

Canadian Council for Refugees. 1998. Best Settlement Practices: Settlement Services for Refugees and Immigrants in Canada, February 1999.

Cummins, Jim. 1996. "Negotiating Identities in the Classroom." Multicultural Teaching, Vol. 15, No.1, pp. 7-11.

Corporation of Delta. 1998. Delta - A Complete Community, pp. 1-4

Delta School District. 1998. Ed Programmes - January 27, 1998, ESL District and School Statistics.

Delta School District. 1996. English as a Second Language. Population Growth and District Response Report.

Delta School District. 1996. Special Programmes Resource Binder, pp. 3-15.

Handford, Penny, LeClerc Sylvain, Fung, Sydney and Wang, Catherine. 1993. Strategic Planning for Immigrant Youth in Surrey and Delta: Report on Phase One. Prepared for Surrey Delta Immigrant Services Society.

Igoa, Cristina. 1995. The Inner World of the Immigrant Child, New York, N.Y.: St. Martin's Press.

Immigrant Services Society of BC. 1993. Settlement in the 1990s: An Overview of the Needs of New Immigrants in the Lower Mainland and Fraser Valley, pp. 2-4.

Minister of Supply and Services Canada. 1988. After the Door has been Opened-Report of the Canadian Task Force on Mental Health Issues Affecting Immigrants and Refugees After the Door has Been Opened, pp. 65-72.

Sayegh, Lilian and Jean-Claude Lasry. 1993. Immigrants' Adaptation in Canada: Assimilation, Acculturation and Orthogonal Cultural Identification, Canadian Psychology, Vol. 34, No. 1, pp. 98-109. ם

\section{Refuge \\ Canada's Periodical on Refugees Available from: Centre for Refugee Studies Fax: (416) 736-5837 Email: refuge@yorku.ca http://www.yorku.ca/research/crs}

